\title{
Incidence of Foramen Vesalius in Adult Human North Indian Crania
}

\author{
${ }^{1}$ Neha Gupta, ${ }^{2}$ Dr. Anjoo Yadav, ${ }^{3}$ Prof. R.J. Thomas, ${ }^{4}$ Ankit Shrivastava \\ ${ }^{1,2,3,4}$ Govt. Medical College, Kannauj (U.P.),India
}

\begin{abstract}
Foramen Vesalius is a small, variable and an inconstant foramen located in the greater wing of sphenoid, anteromedial to the foramen ovale, in the middle cranial fossa. This foramen is also known as emissary sphenoidal foramen as it transmits a small emissary vein which drains Cavernous sinus. The importance of this foramen lies in the fact that an infected thrombus from an extracranial source may reach cavernous sinus.

The present study was undertaken to observe the incidence of foramen Vesalius in the adult human crania in north India. For this purpose, 200 macerated skulls of unknown age and sex were observed. These skulls were obtained from the departments of Anatomy in TeerthankarMahaveer Medical College \& Research Center (Moradabad), King George Medical College (Lucknow), Shri Ram MurtiSmarak Institute Of Medical Science (Bareilly) and Govt. Medical College Kannauj. The foramen Vesalius was found to be present in 68 skulls (ie $34 \%) ;$ out of which it was bilaterally in 28 skulls (14\%) and unilaterally in 40 skulls (20\%)- in 16 skulls on right side and in 24 skulls on left side. The knowledge of foramen Vesalius is important for neurosurgeons and anatomists and anthropologists.
\end{abstract}

Keywords: Foramen Vesalius, middle cranial fossa, skull, sphenoid.

\section{Introduction:}

Foramen Vesalius is a small, variable and an inconstant foramen located anteromedial to the foramen ovale. This foramen is also known as emissary sphenoidal foramen. It opens below and lateral to scaphoid fossa. It transmits an emissary vein, "Vein of Vesalius", through which the cavernous venous sinus and pterygoid venous plexus communicate ${ }^{1}$.Vesalius in his famous book, "De humanicorporisfabrica" describes this foramen with uncommonly subjective language, "because one skull more elegant than the others, belonging to a man of middle age by far the most handsome I have ever seen, displays this foramen",2.

The importance of this foramen is that it offers a path to the spread an infection from the extracranial source to the cavernous sinus. The small FV, if present, is generally situated posteromedially from the foramen rotundum (FR) and anteromedially from the foramen ovale (FO), foramen spinosum (FS), and carotid canal ${ }^{3}$. The FV is located between the FO and FR, but particularly more closely to the FO, and thus neurosurgery may misplace the needle during percutaneous intervention targeting the FO for treatment of the trigeminal neuralgia, resulting in severe complications such as intracranial bleeding ${ }^{4}$.

Therefore, the present study aimed to evaluate the frequency of occurrence and the morphometry of the FV in North India, and these anatomical considerations may assist the surgeon to a better planning and a safer execution of percutaneous approach to the middle cranial fossa through the FO.

\section{Material \&Method :-}

The present study was conducted in the department of Anatomy In Govt. Medical College Kannauj, TeerthankarMahaveer Medical College \& Research Center (Moradabad), King George Medical College (Lucknow), Shri Ram murtiSmarak Institute Of Medical Science (Bareilly).

This study was performed in 200 adult macerated human skulls of Indian individuals of unknown age, sex and damaged skulls were excluded from the study.

The skulls were washed their anterior, superior, posterior, inferior surface properly, cleaned with the help of soft brush and wipe with clean and dry cloth. Thereafter we were observed for Incidence of Foramen Vesalius.

Patency was confirmed by inserting a bristle through each probable foramen, evaluates the Size of foramen by vernier callipers and observed the presence, absence, double and any other variations of foramen. 
Observation :-

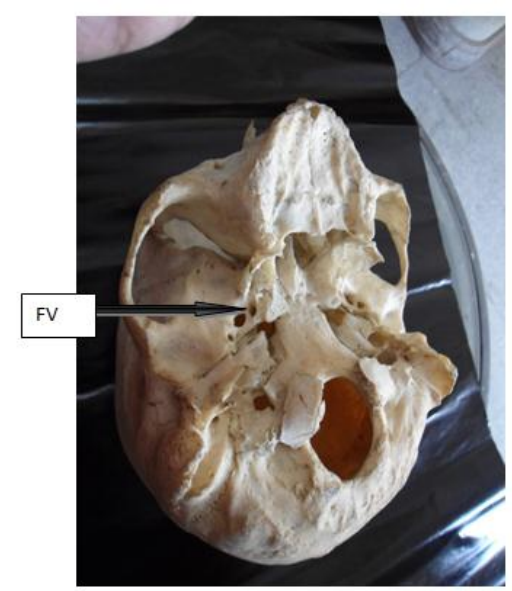

Figure:1 shown FV on Rt side (unilateral)

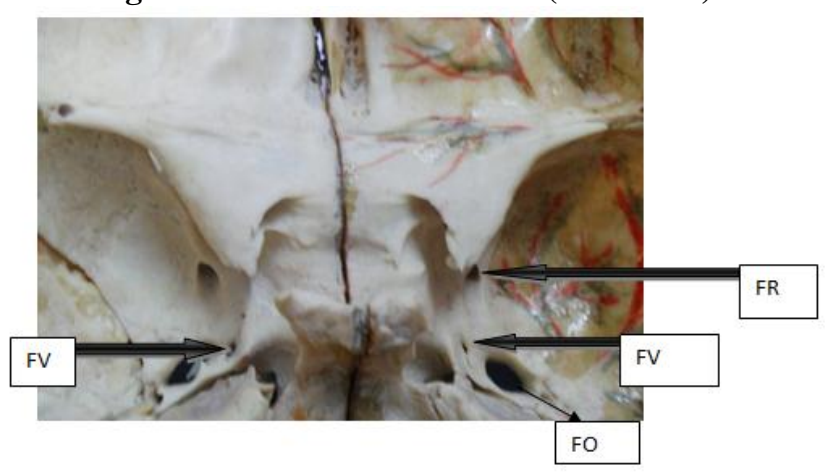

Figure:2shownbilateral FV

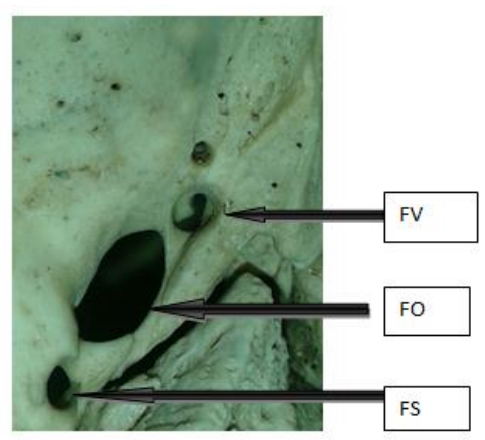

Figure:3 shown FV with different shape

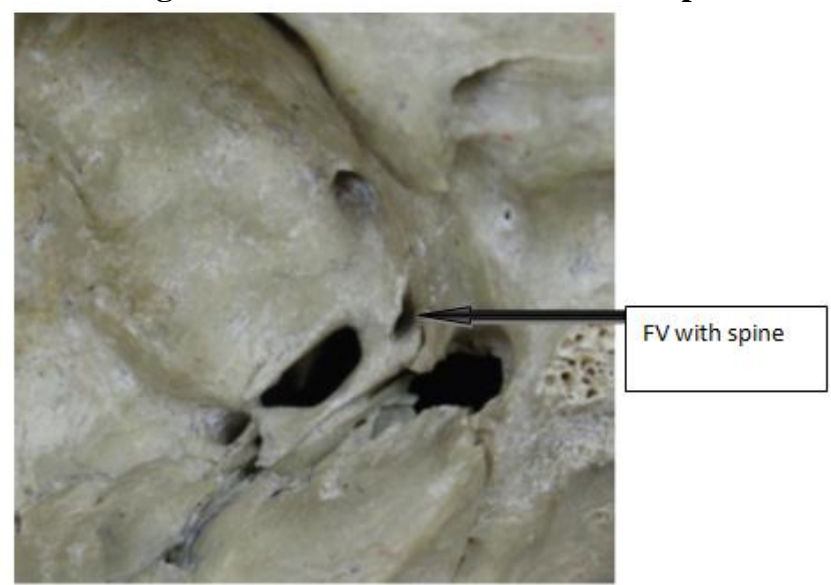

Figure:4 shown FV with spine 


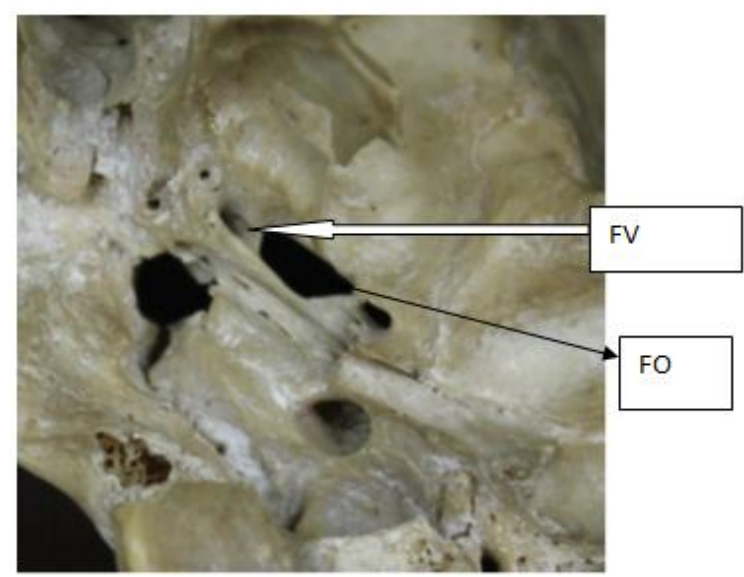

Figure:5 shown FV converge in foramen ovale

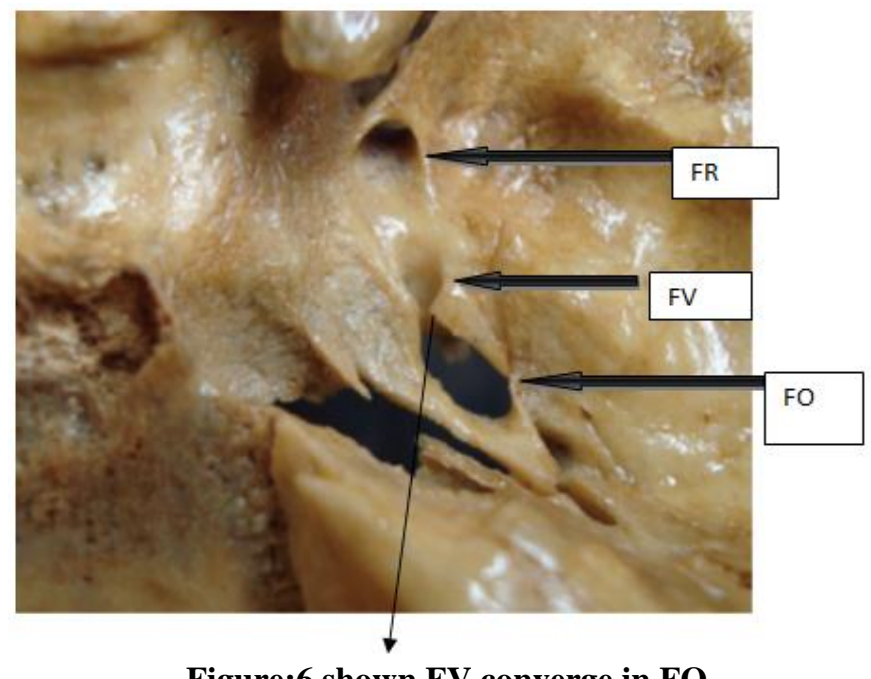

Figure:6 shown FV converge in FO

Table -1 Incidence of foramen vesalius

Table -1 Incidence of foramen vesalius
\begin{tabular}{|l|l|l|l|l|l|}
\hline No. Of skull & Incidence & Unilateral & Bilateral & Rt side & Lt side \\
\hline $200(400$ sides $)$ & $34 \%$ & $20 \%$ & $14 \%$ & $15 \%$ & $19 \%$ \\
\hline
\end{tabular}

Table-2 Distance between FO - FV

\begin{tabular}{|l|l|l|}
\hline No. Of skull & $\begin{array}{l}\text { Right side } \\
\text { Mean } \pm \text { SD }\end{array}$ & $\begin{array}{l}\text { Left side } \\
\text { Mean } \pm \text { SD }\end{array}$ \\
\hline 68 & $1.363 \pm 0.328 \mathrm{~mm}$ & $1.480 \pm 0.378 \mathrm{~mm}$ \\
\hline
\end{tabular}

\section{Discussion:-}

Importance of this foramen lies in the fact that it gives passage to vein of vesalius, an emissary vein. Emissary veins are those, which link the intracranial venous sinuses with veins outside the cranial cavity. They pass through the potential space between galeaaponeurotica and pericranium. They are of importance in that they are channels along which infected thrombus can reach the interior of cranial cavity from outside it. Since emissary vein passing through foramen vesalius connects pterygoid venous plexus with cavernous sinus, the infected thrombus may reach cavernous sinus. Surgical importance of foramen vesalius lies in the fact that during percutaneous trigeminal rhizotomy, needle insertion through the vesalius foramen the cavernous sinus puncture may occur ${ }^{5}$. During development, most of the central skull base bones are preformed in cartilage and then ossify by the process of endochondral ossification with a small contribution from membranous bone. At 11 weeks 5 days the entire skull base is preformed in cartilage and then ossification of skull base progresses in an orderly pattern from posterior to anterior. Postsphenoid and presphenoid centres that appear at 14 weeks form the sphenoid bone and 17 weeks respectively with a contribution from orbitosphenoid and alisphenoid centres that appear at 16 weeks and 15 weeks respectively5. The greater wings are formed from alisphenoid centres. Moreover, it has been shown that the foramen of vesalius represents the site of fusion between the membrane bone and medial cartilaginous, alatemporalis ${ }^{6}$ 
Table of Comparative study of foramen Vesalius:-

\begin{tabular}{|c|c|c|c|c|}
\hline Name of author & Year & Incidence & Bilateral & Unilateral \\
\hline Boyd et al ${ }^{7}$ & 1930 & $36.8 \%$ & $14.7 \%$ & $21.8 \%$ \\
\hline${\text { Bergmen et } \text { al }^{8}}$ & 1995 & $40 \%$ & $35 \%$ & $13 \%$ \\
\hline Berge et al $^{9}$ & 2001 & $59 \%$ & $35 \%$ & $24 \%$ \\
\hline Gupta et $\mathrm{al}^{4}$ & 2005 & $32.58 \%$ & $22.85 \%$ & $20.58 \%$ \\
\hline Kale et al ${ }^{10}$ & 2009 & $45 \%$ & $25 \%$ & $19.9 \%$ \\
\hline Rossi et al ${ }^{11}$ & 2010 & $40 \%$ & $13.76 \%$ & $26.25 \%$ \\
\hline $\begin{array}{l}\text { Vipavadee } \\
\text { et } \text { al }^{12}\end{array}$ & 2012 & $16 \%$ & $4.2 \%$ & $11.9 \%$ \\
\hline Hussain et al ${ }^{13}$ & 2012 & $36 \%$ & $24 \%$ & $16 \%$ \\
\hline Present study & 2014 & $34 \%$ & $14 \%$ & $20 \%$ \\
\hline
\end{tabular}

Bar chart of comparative study of foramen Vesalius:-

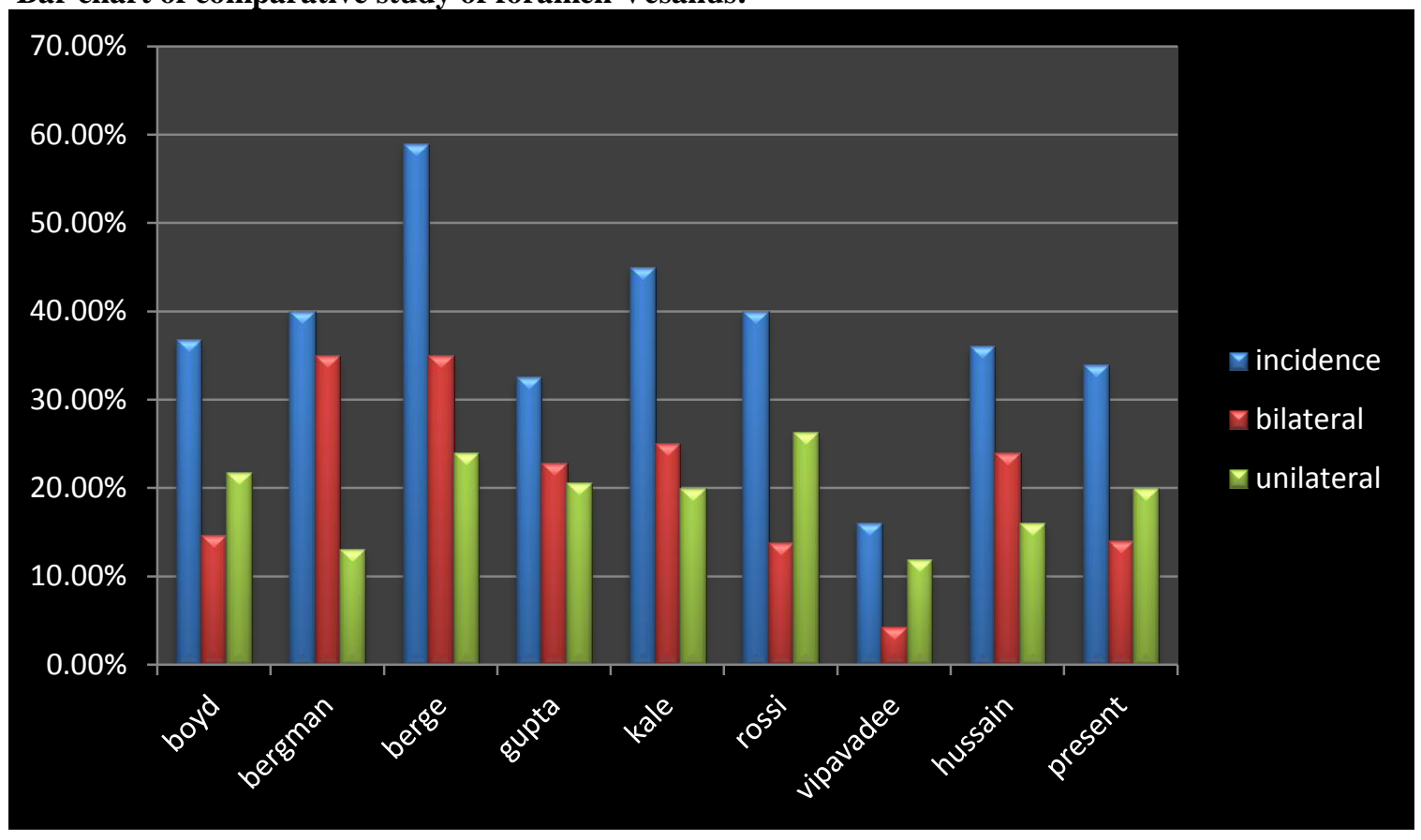

Many studies have reported the incidenceof the foramen of Vesalius and noted that thisforamen may have variations. According toByod et $\mathrm{al}^{7}$ (1930) found 36.8\%, Lang $^{14}$ (1883) and Bergman ${ }^{8}$ et al(1995), theforamen found in $40 \%$ of cases, Williams et al.(1995) found foramen in $8.5 \%$ cases,Kodama ${ }^{3}$ et al.(1997) found in $21.75 \%$ cases, Berge ${ }^{9}$ et al(2001) found foramen in 59\%, Gupta etal ${ }^{4}$ (2005) found in $32.85 \%$ of cases Wysocki etal $^{15}$ (2007) reported in $22 \%$ of cases, ,Ramalho etal ${ }^{16}(2007)$ with analysis on 64 human skullsobtained incidence of $71.87 \%$ and Kalpan et $\mathrm{al}^{7}(2007)$ who obtained $100 \%$ incidence but with only 10 skulls examined,Kale et $\mathrm{al}^{10}(2009)$ found in $45 \%$, ,Shinohara et $\mathrm{al}^{17}$ (2010) found the foramen to $33.75 \%$ in 400skulls, Rossi etal ${ }^{11}$ (2010) found in 40\%,Vipavadee et al ${ }^{12}$ (2012)found in $16 \%$, Hussain et al ${ }^{13}$ (2012) found in $36 \%$ and present study found $34 \%$ in 200 skull which is higher thenwilliams etal, kodama et al, wysocki et al, gupta et al, shinhora et al, vipavadee et al and lower then Long et al, Bergman et al, Ramalho et al, Byod et al, Berge et al, Kale et al, Rosi et al. In this study we have seen that different different shape and types of foramen vesalius which is " 8 " shaped, a foramen converge in to the foramen ovale and a forame with spine .

The presence of foramen vasalius bilaterally(as shown in figure no. 2) was reported byByod et al ${ }^{7}$ (1930) found in $14.7 \%$, Bergman et $\mathrm{al}^{8}$ (1995) found in 35\%, Berge et $\mathrm{al}^{9}(2001)$ in 35\%,gupta et $\mathrm{al}^{4}(2005)$ in $22 . \%$, Kale et $\mathrm{al}^{10}$ (2009) in $25 \%$, Shinohara et $\mathrm{al}^{17}(2010)$ in $12.5 \%$, Rossi et al ${ }^{11}$ (2010) in 13.76, Vipavadee et al ${ }^{12}$ (2012) found in $4.2 \%$, Hussain et $\mathrm{al}^{13}$ (2012) in $24 \%$, and in present study found $14 \%$ in 200 skulls which is grater then Shinohara et al, Rossi et al ,Vipavadee et al and lesser then Boyd wt al , Bergman et al, Berge et al, Gupta et al, Kale et al, and Hussain et al.

The presence of formenvasalius unilaterally(as shown in figure no. 1) was reported by Byod et $\mathrm{al}^{7}$ (1930) in found $21.8 \%$, Bergman et $\mathrm{al}^{8}(1995)$ in $13 \%$ of cases, according to study by Kodma et $\mathrm{al}^{3}$ (1997) was $5.5 \%$, Berge et $\mathrm{al}^{9}$ (2001) found in $24 \%$, Gupta et $\mathrm{al}^{4}$ (2005) found in $20.58 \%$, Kale et al ${ }^{10}$ (2009) found in $19.9 \%$, Rossi et $\mathrm{al}^{11}$ (2010) found in $26.25 \%$, Shinohora et $\mathrm{al}^{17}(2010)$ found occurrence of unilateral foramen 
vasalius in $18.25 \%$ of cases,Vipavadee et $\mathrm{al}^{12}(2012)$ found in $11.9 \%$, Hussain et $\mathrm{al}^{13}$ (2012) found $15 \%$, and in persent study found $20 \%$ in 200 skulls we found that our incidence of unilaterally presnt foramen is higher than Bergmanet al, Gupta et al, Kale et al, Vipavadee et al, Hussain et al and lesser then Byod et al, Berge et al, Rossi et al.

Regarding incidence of foramen vesalius Lang et al ${ }^{14}(1883)$ found the foramen in $49 \%$ of skulls on the right side and $36 \%$ on the left side, Gupta et $\mathrm{al}^{4}(2005)$ found foramen in $20 \%$ right side and $12.85 \%$ on the left. Shinohara et $\mathrm{al}^{17}$ (2010)found an incidence of $7.75 \%$ on the right side and $10.5 \%$ on the left. Shinohara et $\mathrm{al}^{17}$ (2010) was the presence of a double foramen was observed in 7 of the 400 skulls examined, Rossi et al ${ }^{11}(2010)$ found foramen in $15.62 \%$ right side and $11.25 \%$ in left side, Vipavadee et $\mathrm{al}^{12}(2012)$ found in $9.31 \%$ right side and $11.25 \%$ left side, and present study found 15\% in right side and 19\% in left side in 400 sides of skulls(200 skulls) which is more than Shinohara et al and less then Lang et al, Gupta et al, Rossi et al in right side incidence and left side incidence in present is more than Gupta et al,Shinohara et al,Rossi et al and lesser then Lang et al. In this study, we found $\mathrm{FV}$ at a distance to the $\mathrm{FO}$ was $1.363 \pm 0.328 \mathrm{~mm}$ on right side and $1.480 \pm 0.378 \mathrm{~mm}$ on left side.Rossi et $\mathrm{al}^{11}$ (2010) found $1.853 \pm 0.303 \mathrm{~mm}$ on right side and $2.464 \pm 0.311 \mathrm{~mm}$ on left side, Shinohara et $\mathrm{al}^{17}$ (2010) found $3.15 \pm 1.64 \mathrm{~mm}$ on right side and $2.53 \pm 1.30 \mathrm{mmon}$ left side, Vipavadee et $\mathrm{al}^{12}(2012)$ found $2.05 \pm 1.17 \mathrm{~mm}$ on right side and $2.464 \pm 0 . .311 \mathrm{~mm}$ on left side. We didn’t found any significant difference between present study and Rossi, Shinohara, Vipavadee .

In this study we have seen different different shape and types of foramen vesalius which is " 8 " shaped, a foramen converge in to the foramen ovale and a foramen with spine (shown in figure no.3,4,5and 6)

\section{Conclusion:-}

Owing to being a small and inconstant foramen, the FV is not routinely in attention during surgery. The knowledge of the occurrence of the FV may assist the neurosurgeon to realize that the FV is located very close to the FO, particularly at the extracranial view of the skull base. Therefore, in case it exists, the approach through the FO could be the more complicated procedure and the operation should be carefully performed to avoid the FV puncture.

\section{Reference:}

[1]. WillamsPL.,BannisterLH,Martin MM et al.(1998) Gray’ Anatomy(39ed.) Churchill Livigstone, London, pp-455-461.

[2]. Hast MH, Garrison DH.(2000) "Vesalius on variability of the Human Skul"l: Book I, Chapter V of De humanicorporisfabrica. ClinAnat 2000; 13:311-20

[3]. K. Kodama, K. Inoue, M. Nagashima, G. Matsumura, S. Watanabe, and G. Kodama, "Studies on the foramen vesalius in the Japanese juvenile and adult skulls," Hokkaido IgakuZasshi, vol. 72, no. 6, pp. 667-674, 1997.

[4]. N. Gupta, B. Ray, and S. Ghosh, "Anatomic c haracteristics of foramen vesalius," Kathmandu UniversityMedical Journal, vol. 3, no. 10, pp. 155-158, 2005.

[5]. Decker Gag and du Plesis DJ (1986) McGregor's synopsis of surgical anatomy. 12th edn. John wright \& sons ltd. bristol. pp:328333.

[6]. Nemzek WR, Brodie HA, Hecht ST, Chong BW, Babcook CJ and Seibert JA (2000) MR, CT, and plain film imaging of the developing skull base in fetal specimens. Amer. J. Neuroradi. 21,1699-1706.

[7]. G. I. Boyd, "The emissary foramina of the cranium in man and the anthropoids," Journal of Anatomy, vol. 65, pp. 108-121, 1930.

[8]. Bergman RA, Afifi AK and Miyauchi R (1995) Illustrated encyclopedia of human anatomic variation: Opus V: skeletal systems: cranium. sphenoid bone.

[9]. Berge JK, Bergman RA (2001). Variations in size and in symmetry of foramina of the human skull. Clinical Anatomy. 14(6) 406413.

[10]. Kale Aysin, AksuFunda et al (2009) “Foramen of vesalius" Saudi Med J vol.30,(1),pp. 56-59

[11]. C. Rossi, A. R. Freire, F. B. Prado, P. H. F. Caria, and P. R. Botacin, "Morphological characteristics of foramen of Vesalius and its relationship with clinical implications," Journal ofMorphological Sciences, vol. 27, no. 1, pp. 26-29, 2010

[12]. ChaisuksuntVipavadee, KwathaiLanaprai et al (2012) " occurrence of foramen of vesalius and its morphometry relevant to clinical consideration" The scientific World Journal vol.2012, artcle ID 817454,5 pages

[13]. Hussain SahebShaik , Muralidhar P Shepur et al (2012) "Study of foramen vesallius in south indian skulls" Indian Journal Of Medicine and Healthcare vol.1 no.1.

[14]. Lang J (1883) Clinical anatomy of the head, neurocranium, orbit and craniocervical region. Springer-Verlag, Berlin.

[15]. Wysocki J, Reymond J, Skarzynski H andWrobel B (2006) The size of selected human skull foramina in relation to skull capacity.FoliaMorphologica. 66(4), 301-308.

[16]. Ramalho A, Sousa Rodarigues C, Rodas, Delima, Almeida, Neto and Jabs (2007) A incidência e as relaçõesmorfométricas do forameemissário do esfenóideemcrânios humanos. Int. J. Morphology. 25 (1), 145.

[17]. Shinohara AL, de Souza Melo CG, Silveira EM, Lauris JR, Andreo JC and de CastroRodrigues A (2010) Incidence, morphology and morphometry of the foramen of vesalius: complementary study for a safer planning and execution of the trigeminal rhizotomy technique. Surg. Radiol. Anat. 32(2),159-164. 